\title{
Anti-diabetic drugs prescription pattern by postgraduate students among type 2 diabetes patients attending a tertiary care hospital
}

\author{
Lohit K. ${ }^{1}$, Lakshmish Devang Halepalya Somashekar ${ }^{2}$, \\ Naveen Kumar ${ }^{2}$, Vidya K. R. ${ }^{3 *}$
}

${ }^{1}$ Department of Pharmacology,

${ }^{3}$ Department of Community

Medicine, Sri Siddhartha

Institute of Medical Sciences and Research Center, Bangalore Rural, Karnataka, India ${ }^{2}$ Department of Pharmacology, Sri Siddhartha Medical College, Tumkur, Karnataka, India

Received: 20 August 2019

Revised: 03 October 2019

Accepted: 05 October 2019

*Correspondence to:

Dr. Vidya K. R.,

Email: vidya.287@gmail.com

Copyright: (C) the author(s), publisher and licensee Medip Academy. This is an openaccess article distributed under the terms of the Creative Commons Attribution NonCommercial License, which permits unrestricted noncommercial use, distribution, and reproduction in any medium, provided the original work is properly cited.

\begin{abstract}
Background: The pattern of prescribing anti-diabetic drugs varies among different medical professionals due to the availability of numerous anti-diabetic drugs and demographic and have increasingly favoured for tighter control of glycemic index. Even with the available multiple therapies many patients are not in control. The reasons may be multi factorial and the one important factor is the drugs prescribed.

Methods: This cross-sectional study involving 140 type 2 adult diabetes patients was done to assess the pattern of anti-diabetic drugs prescribed by the postgraduate students in a tertiary health care center using a specially designed questionnaire.

Results: Oral medications were predominantly prescribed. Metformin and Glimepiride combination was prescribed in majority. Among insulin, combination of short and intermediate acting insulin was prescribed more and the number of insulin prescription increased with the duration of diabetes. Interestingly no newer classes of drugs are prescribed.

Conclusions: There is a rational prescription pattern of antidiabetic drugs but newer antidiabetic drugs are not prescribed and life style changes are not discussed with the patients. There is a need to include life style changes as a part of prescription to all the patients.
\end{abstract}

Keywords: Anti-diabetic drugs, Diabetes, Prescription pattern, Postgraduate students

\section{INTRODUCTION}

Diabetes mellitus is a major health problem affecting more than 62 million individuals in India. ${ }^{1,2}$ The management of multiple etiology factors of diabetes is a major challenge and should focus on genetic factors coupled with environmental influences such as rising living standards, steady urban migration and lifestyle changes. ${ }^{3}$ The risk of diabetic complications was strongly associated with previous hyperglycemia. As the disease advances the micro and macro vascular complications like retinopathy, nephropathy, diabetic neuropathy and coronary vascular diseases will complicate the management and also the well-being of the patient. ${ }^{4}$ Small reduction in $\mathrm{HbA}_{1 \mathrm{c}}$ levels leads to major reduction in complications. ${ }^{5}$ Patient with diabetes needs to adhere to the individualized medications and has to undertake sufficient life style changes like exercise and diet to increase the total energy expenditure to $160-180 \%$ of their resting metabolic rate. ${ }^{6,7}$

Hence the pattern of prescribing anti diabetic drugs for type 2 diabetes mellitus have increasingly favored for tighter control of glycemic index, so aggressive 
pharmacotherapy has been used in the recent times. ${ }^{8-12}$ Even with the aggressive therapy $52.85 \%$ of patients are not in control. The reasons may be multi factorial and the one important factor is the drug prescribed and its adherence.

This study is focused to evaluate the prescription pattern of anti-diabetic drugs by postgraduates in a tertiary care hospital. These postgraduate students are being exposed to the diabetic patients for the first time after graduation. Hence the knowledge of how drugs are prescribed just after the graduation of doctors will help in identifying concerns if any addressing rational drug use or suggest measures to improve prescribing habits after their graduation. $^{13}$

\section{METHODS}

This cross sectional observational study was conducted in Sri Siddhartha Medical College, a tertiary care centre in Tumakuru, southern part of India from April to December 2016. An ethics committee approval and permission from the hospital authorities has been obtained prior the study. Data was collected using a specially designed questionnaire post prescription to the diabetic patients by the post graduate medicine students. To avoid the prescription bias the data was collected once the patient came out of consultation.

\section{Inclusion criteria}

All consented type 2 diabetic patients aged $\geq 18$ years appearing to outpatient department for the management

were selected by convince sampling method were included in the study.

The data regarding demographic profile, diabetes and the drugs prescribed was collected from 140 patients and analysed using SPSS using descriptive statistics.

\section{RESULTS}

A total of 140 type 2 diabetic patients aged between 40 to 80 years were included. Among them $51.4 \%$ were in age range of 51 to 60 years. Most of them were males $58.6 \%$ and $27.2 \%$ were illiterate. Majority of patients, $62.9 \%$ were diagnosed recently within 5 years (Table 1 ).

Table 1: Socio demographic details of study subjects.

\begin{tabular}{|c|c|c|c|}
\hline \multirow{2}{*}{ Parameters } & & \multicolumn{2}{|l|}{ Total } \\
\hline & & Number & $\%$ \\
\hline \multirow{4}{*}{ Age (in years) } & $40-50$ & 18 & 12.9 \\
\hline & $51-60$ & 72 & 51.4 \\
\hline & $61-70$ & 44 & 31.4 \\
\hline & $71-80$ & 6 & 4.3 \\
\hline \multirow{2}{*}{ Gender } & Male & 82 & 58.6 \\
\hline & Female & 58 & 41.4 \\
\hline \multirow{3}{*}{ Education } & Illiterate & 38 & 27.2 \\
\hline & Upto SSLC & 58 & 41.4 \\
\hline & SSLC and above & 44 & 31.4 \\
\hline \multirow{3}{*}{$\begin{array}{l}\text { Years with } \\
\text { diabetes }\end{array}$} & $<5$ & 88 & 62.9 \\
\hline & $5-10$ & 40 & 28.6 \\
\hline & $>10$ & 12 & 8.5 \\
\hline \multirow{2}{*}{$\begin{array}{l}\text { Co- } \\
\text { morbidities }\end{array}$} & Present & 74 & 52.8 \\
\hline & Absent & 66 & 47.2 \\
\hline
\end{tabular}

Table 2: Antidiabetic drugs prescription with respect to age group.

\begin{tabular}{|c|c|c|c|c|c|c|}
\hline \multirow{2}{*}{ Route } & \multirow{2}{*}{ Drugs prescribed } & \multirow{2}{*}{$\begin{array}{l}\text { Total patients } \\
\mathbf{N}(\%)\end{array}$} & \multicolumn{4}{|c|}{ Age groups (years) } \\
\hline & & & $40-50$ & $51-60$ & 61-70 & 70-80 \\
\hline \multirow{6}{*}{$\begin{array}{l}\text { Only } \\
\text { oral }\end{array}$} & Metformin & $28(28.0)$ & 6 & 20 & 2 & 0 \\
\hline & Glimepiride & $16(16.0)$ & 2 & 14 & 0 & 0 \\
\hline & Voglibose & $08(08.0)$ & 2 & 6 & 0 & 0 \\
\hline & Metformin+ glimepiride & $44(44.0)$ & 6 & 26 & 12 & 0 \\
\hline & Metformin+ glimepiride+voglibose & $04(04.0)$ & 0 & 0 & 4 & 0 \\
\hline & Total & 100 & & & & \\
\hline \multirow{4}{*}{$\begin{array}{l}\text { Only } \\
\text { insulin }\end{array}$} & Short acting & $00(0.00)$ & 0 & 0 & 0 & 0 \\
\hline & Long acting & $02(20.0)$ & 0 & 0 & 2 & 0 \\
\hline & Short + long acting & $08(80.0)$ & 0 & 4 & 4 & 0 \\
\hline & total & 10 & & & & \\
\hline \multirow{7}{*}{$\begin{array}{l}\text { Oral } \\
+ \text { insulin }\end{array}$} & Metformin+short acting insulin & $06(04.3)$ & 2 & 0 & 4 & 0 \\
\hline & Metformin+mixed insulin & $10(07.2)$ & 0 & 0 & 8 & 2 \\
\hline & Glimepiride+short acting insulin & $02(01.4)$ & 0 & 2 & 0 & 0 \\
\hline & Glimepiride +mixed insulin & $02(01.4)$ & 0 & 0 & 2 & 0 \\
\hline & Voglibose +mixed insulin & $02(01.4)$ & 0 & 0 & 2 & 0 \\
\hline & Metformin+glimepiride+short acting insulin & $02(01.4)$ & 0 & 0 & 2 & 0 \\
\hline & Metformin+glimepiride+mixed insulin & $06(04.3)$ & 0 & 0 & 2 & 4 \\
\hline \multicolumn{2}{|c|}{ Total patients } & $140(100)$ & 18 & 72 & 44 & 6 \\
\hline
\end{tabular}


Table 3: Percentage of drugs prescribed with respect to duration of diabetes.

\begin{tabular}{|c|c|c|c|c|c|}
\hline \multirow{2}{*}{ Route } & \multirow{2}{*}{ Drugs prescribed } & \multicolumn{3}{|c|}{ Duration of diabetes } & \multirow{2}{*}{$\begin{array}{l}\text { Total patients } \\
\mathbf{N}(\%)\end{array}$} \\
\hline & & $<5$ years & 5-10 years & $>10$ years & \\
\hline \multirow{5}{*}{$\begin{array}{l}\text { Only } \\
\text { oral }\end{array}$} & Metformin & 28 & 0 & 0 & $28(20.0)$ \\
\hline & Glimepiride & 14 & 2 & 0 & $16(11.4)$ \\
\hline & Voglibose & 8 & 0 & 0 & $08(05.7)$ \\
\hline & Metformin + glimepiride & 32 & 10 & 2 & $44(31.4)$ \\
\hline & Metformin + glimepiride + voglibose & 2 & 2 & 0 & $04(02.8)$ \\
\hline \multirow{3}{*}{$\begin{array}{l}\text { Only } \\
\text { insulin }\end{array}$} & Short acting & 0 & 0 & 0 & $00(0.00)$ \\
\hline & Long acting & 0 & 2 & 0 & $02(01.4)$ \\
\hline & Short + long acting & 2 & 4 & 2 & $08(05.7)$ \\
\hline \multirow{7}{*}{$\begin{array}{l}\text { Oral + } \\
\text { insulin }\end{array}$} & Metformin + short acting insulin & 2 & 2 & 2 & $06(04.3)$ \\
\hline & Metformin + mixed insulin & 0 & 8 & 2 & $10(07.2)$ \\
\hline & Glimepiride + short acting insulin & 0 & 2 & 0 & $02(01.4)$ \\
\hline & Glimepiride + mixed insulin & 0 & 2 & 0 & $02(01.4)$ \\
\hline & Voglibose + mixed insulin & 0 & 2 & 0 & $02(01.4)$ \\
\hline & Metformin + glimepiride + short acting insulin & 0 & 2 & 0 & $02(01.4)$ \\
\hline & Metformin+glimepiride+mixed insulin & 0 & 2 & 4 & $06(04.3)$ \\
\hline \multicolumn{2}{|c|}{ Total patients } & 88 & 40 & 12 & $140(100)$ \\
\hline
\end{tabular}

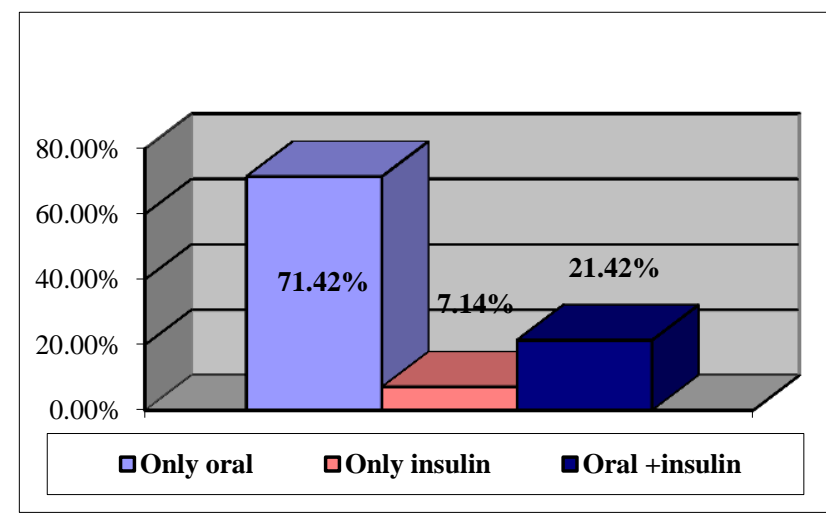

Figure 1: Antidiabetic drugs prescription pattern.

Out of 140 prescriptions of antidiabetic drugs studied, $71.4 \%$ were on only oral medications. Among them 44\% were on dual drug (metformin and glimepiride) therapy and $52 \%$ were on single drug therapy which includes metformin $28 \%$, glimepiride $16 \%$ and voglibose $8 \%$. Only $28.57 \%$ were on insulin therapy constituting $7.14 \%$ on insulin only therapy and $21.43 \%$ on combination of insulin and oral drugs and metformin with mixed insulin was most commonly prescribed among them (Figure 1, Table 2).

On comparing the duration of diabetes with the drugs prescribed, oral drugs were prescribed more among patients with shorter duration of diabetes. Insulin prescription increased from $4.54 \%$ among $<5$ year duration of diabetes to $65 \%$ in 5 to 10 years and $83.33 \%$ of patients with more than 10 years of diabetes (Table 3 ).

Among patients treated with only oral medication and with combination of insulin with oral medications, $46 \%$ and $86.6 \%$ of patients had co morbidities respectively.
Among patients with no oral medications, long acting insulin was prescribed only to patients with no comorbidities and the combination of short and intermediate acting insulin was prescribed to $25 \%$ patients with co morbidities (Figure 2).

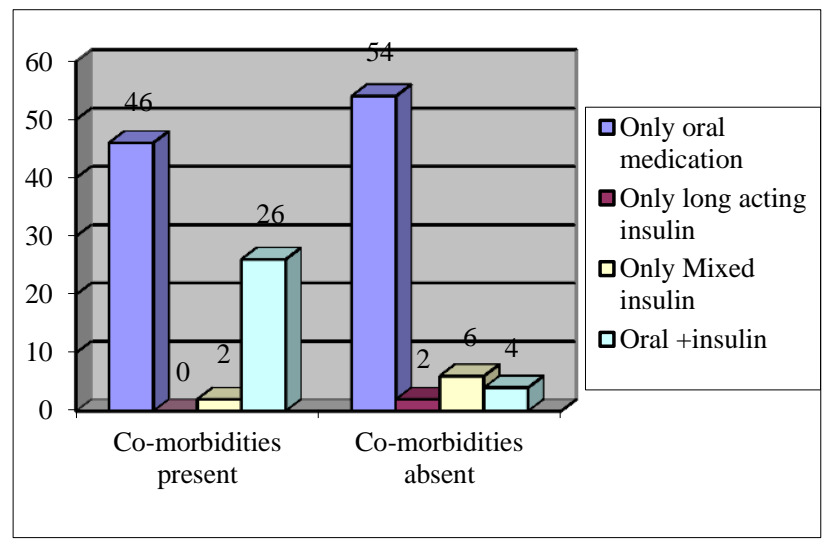

Figure 2: Prescription pattern in relation to co morbidities.

\section{DISCUSSION}

In the current study, more than $80 \%$ of the participants belonged to the age more than fifty years. Even though the diabetes affects all age group, the elderly generality in the current study may be due to their preference to the hospital or participants time to visit hospital during working hours. Male preponderance may be due to the underlying socio cultural factors and life styles changes among men and women which results in steady increase in body weight, higher energy intake and reduced energy expenditure in male. ${ }^{14}$ The gender ratio was found similar to various studies conducted in india. ${ }^{11}$ 
According to the American diabetes association guidelines, lifestyle changes should be the first line of therapy and when this has not achieved glycemic goals then need to add oral antidiabetic agents. Life style changes were not written in the prescriptions of the patients and the main focus was on drug therapy. The individualized life style changes were not explained to the patients.

Most of the patients were exclusively on oral anti diabetic drugs which is similar to study conducted in Bengal. ${ }^{15}$ Since most of the subjects were selected on regular outpatient department basis. The dual drug therapy of glimepiride with metformin was prescribed more compared to monotherapy and is similar to a study conducted in taiwan. ${ }^{16}$ Metformin was prescribed as the single drug therapy in $20 \%$ and glimepiride in $11 \%$. The choice of the monotherapy may be due to its affordability, less side effects, effects on weight and other pharmacokinetic parameters. ${ }^{17}$ Interestingly newer drugs like gliptins, SGLT2 inhibitors, thiazolidinediones were not prescribed to any patients. The reasons for the lower use of thiazolidinediones and other oral antidiabetic drugs in our study are not known. The reason may be cost of the drugs, early stage of diabetes, no good exposure for the doctor with newer drugs or lack of update on diabetes management. But this need to be explored as the treatment is limited only to metformin, glimepiride and voglibose.

Insulin was prescribed to $28.5 \%$ of patients and among them $7.1 \%$ received insulin alone therapy and $21.4 \%$ combination of oral anti diabetic drugs and insulin therapy. Most of the participants selected in the study have diabetes from less than 5 years so the preferred choice of treatment was oral anti diabetic drugs and combinations of antidiabetics are prescribed to achieve a better glycemic control in order to avoid long term complication. Participants who were prescribed insulin alone, long acting insulin and premixed insulin was prescribed in $20 \%$ and $80 \%$ participants respectively. Preferably the insulin initiation is to begin with longacting insulin in combination with other oral antidiabetic drugs. Rapid or short-acting insulin at mealtime can be added if the desired postprandial glucose targets are not achieved but more patients were prescribed with combination of short and intermediate acting insulin. A combination of metformin and premixed insulin was prescribed in $7.2 \%$ participants and metformin with short acting insulin was prescribed in $4.3 \%$. Interestingly glimepiride or voglibose is combined with insulin among $4.3 \%$ patients without any sensitizers.

In the present study, it was found that co morbidities were present in $52.8 \%$ participants which differs from a study done in Bengal where co morbidities was present in $74 \%$ participants. ${ }^{15}$ Most of the patients involved in the study belong to 51-70 age group and duration of diabetes in them was less than 5 years so comorbidities present in participants was found to be less. A prospective study will have a better picture of the effectiveness of a drug and if we record the Hba1c value, which helps us to prescribe the appropriate drug at the right dose. Unfortunately due to cost factor, patients $\mathrm{HbA} 1 \mathrm{c}$ values and other investigations to look for complications were not done.

\section{Merits of the study}

As drug prescription study is the most effective method to assess and to evaluate the prescribing attitude of doctors and helps to promote the rational use of drugs. The present study will help to know the pattern of prescription by the post graduate students.

Cheaper drugs were prescribed in all the patients. It helps to promote rational use of drugs.

\section{Demerits of the study}

Our data did not include patient's main diagnoses and comorbidities that may affect how prescription pattern are interpreted. We had not recorded socio economic status of patients which may affect the prescription pattern. The multi centric study will give more insights with respect to prescription of drugs.

Oral antidiabetic agents were commonly prescribed than injectables. Metformin and Glimepiride combination was prescribed in majority of patients. Among insulin, premixed insulin was maximally prescribed. Newer antidiabetics were not prescribed and life style changes were not explained to the diabetic patients.

\section{Recommendations}

There is a need for continuous education for a progressive change in prescription of antidiabetic drugs in accordance with the guidelines. Orientation to insulin therapy including initiation, continuation and also combination with other drugs is required. Life style changes which form the most important part for the management should be stressed at every patient visit to the doctors

\section{CONCLUSION}

This study has shown that metformin is the predominantly prescribed oral antidiabetic drug both as monotherapy as well as combination therapy. Overall, monotherapy was predominant over combination therapy. Glimepride and Metformin combination was the most commonly prescribed combination therapy. This study revealed that the antidiabetic prescription pattern was rational but newer antidiabetic drugs and life style changes were not prescribed to the patients. There is a need to include life style changes discussion as a part of prescription to all the patients.

\section{ACKNOWLEDGEMENTS}

We wish to express our profound gratitude to the faculty and staff of Sri Siddartha Medical College for their contributions to conduct this study. We also thank and 
acknowledge Dr. Ashwin for helping in collecting the data and all the participants involved.

Funding: No funding sources

Conflict of interest: None declared

Ethical approval: The study was approved by the Institutional Ethics Committee

\section{REFERENCES}

1. Joshi SR, Parikh RM. India diabetes capital of the world: now heading towards hypertension. J Assoc Physicians India. 2007;55:323-4.

2. Kumar A, Goel MK, Jain RB, Khanna P, Chaudhary V. India towards diabetes control: Key issues. Australas Med J. 2013;6(10):524-31.

3. Kaveeshwar SA, Cornwall J. The current state of diabetes mellitus in India. Aust Med J. 2014;7(1):458.

4. Fowler MJ. Microvascular and Macrovascular Complications of Diabetes. Clin Diabetes. 2008;26(2):77-82.

5. Stratton IM, Adler AI, Neil HAW, Matthews DR, Manley SE, Cull CA, et al. Association of glycaemia with macrovascular and microvascular complications of type 2 diabetes (UKPDS 35): prospective observational study BMJ. 2000;321:405.

6. Flegal KM, Carroll MD, Ogden CL, Johnson CL. Prevalence and Trends in Obesity Among US Adults, 1999-2000. JAMA. 2002;288(14):1723-7.

7. Mokdad AH, Ford ES, Bowman BA, Dietz WH, Vinicor F, Bales VS, et al. Prevalence of Obesity, Diabetes, and Obesity-Related Health Risk Factors, 2001. JAMA. 2003;289(1):76-9.

8. Qaseem A, Vijan S, Snow V, Cross JT, Weiss KB, Owens DK. Glycemic control and type 2 diabetes mellitus: the optimal hemoglobin A1c targets. A guidance statement from the American College of Physicians. Ann Intern Med 2007;147(6):417-22.

9. American Diabetes Association. Diabetes Care 2008;31(Supplement 1):S12-S54.

10. Ryden L, Standl E, Bartnik M, Van den Berghe G, Betteridge $\mathrm{J}$, de Boer MJ, et al. Guidelines on diabetes, prediabetes, and cardiovascular diseases:executive summary. The Task Force on Diabetes and Cardiovascular Diseases of the European Society of Cardiology (ESC) and of the European Association for the Study of Diabetes (EASD). Eur Heart J. 2007;28(1):88-136.

11. Canadian Diabetes Association Clinical Practice Guidelines Expert Committee. Canadian Diabetes Association 2003 clinical practice guidelines for the prevention and management of diabetes in Canada. Canadian J Diabetes. 2003;(S2):27.

12. Lawrenson R. Standards of medical care in diabetes: Diabetes Care. 2005;28(Suppl 1):S4-S36.

13. Ashutosh K, Ipseeta RM, Sandeep R. Assessment of Prescription Pattern of Antidiabetic Drugs in the Outpatient Department of a Tertiary Care Hospital. Int J Clin Endocrinol Metab. 2017;3(1):1-7.

14. Ginter E, Simko V. Type 2 diabetes mellitus, pandemic in 21st century. Adv Exp Med Biol. 2012;771:42-50.

15. Mandal S, Maiti T, Das AK, Das A, Mandal A, Sarkar BS, et al. Drug utilization study in patients with type 2 diabetes mellitus diabetes clinic of a tertiary care hospital in rural Bengal. Int J Basic Clin Pharmacol. 2016;5:1647-54.

16. Chu WM, Ho HE, Huang KH, Tsan YT, Liou YS, Wang YH, et al. The prescribing trend of oral antidiabetic agents for type 2 diabetes in Taiwan:An 8-year population-based study. Medicine. 2017;96(43):e8257.

17. Uma DP, Alex SM, Sreelekshmi BS, Smitha S, Jiji KN, Menon AS. Drug Utilization Pattern Of Antidiabetic Drugs Among Diabetic Outpatients In A Tertiary Care Hospital. Asian J Pharm Clin Res. 2015;8(2):144-6.

Cite this article as: Lohit K, Somashekar LDH, Kumar N, Vidya KR. Anti-diabetic drugs prescription pattern by postgraduate students among type 2 diabetes patients attending a tertiary care hospital. Int J Basic Clin Pharmacol 2019;8:2454-8. 